\title{
Corneal epithelial permeability during extended wear of disposable contact lenses versus daily wear of soft contact lenses
}

\author{
L R H M Schurmans, E P M Boets, J A van Best
}

\begin{abstract}
Aims-The corneal epithelial permeability during extended wear of disposable contact lenses was compared with that during daily wear of soft contact lenses. The study was performed to verify whether the extended wear of disposable contact lenses would result in a higher permeability value than the daily wear of soft contact lenses. A higher permeability makes the cornea more vulnerable for bacterial infections and thus could explain the higher incidence of bacterial keratitis found in extended wear of disposable contact lenses in comparison with the daily wear of soft contact lenses.

Method-The corneal epithelial permeability was determined by fluorophotometry in 33 healthy volunteers after the wear of soft, daily wear contact lenses for at least 6 months. Thereafter the determination was repeated in each volunteer after extended wear of disposable contact lenses for 1 month. The permeability in 34 healthy non-contact lens wearing volunteers was determined as a control. The permeability value was calculated from the amount of fluorescein that passed into the cornea after application by means of an eyebath.

Results-The mean permeability values after daily and extended wear were $0.032 \mathrm{~nm} / \mathrm{s}$ and $0.031 \mathrm{~nm} / \mathrm{s}$, respectively. The values were not significantly different (Wilcoxon paired test $\mathbf{p}>0.5$ ). The mean permeability for the non-contact lens wearing controls was $0.042 \mathrm{~nm} / \mathrm{s}$.

Conclusion-The results do not sustain the explanation that a difference in permeability value is the main cause of the increased incidence of keratitis during extended wear of disposable contact lenses in comparison with daily wear.
\end{abstract}

Department of Ophthalmology, University Hospital Leiden,

Rijnsburgerweg 10 , 2333 AA Leiden, the Netherlands L R H M Schurmans E P M Boets $\mathrm{J} A$ van Best

Correspondence to: $\mathrm{J} A$ van Best, $\mathrm{PhD}$ Department of Ophthalmology, University Hospital Leiden, PO Box 9600,2300 RC Leiden, the Netherlands.

Accepted for publication 9 December 1994

the sight threatening complications caused by the wear of soft contact lenses, such as bacterial keratitis and corneal ulcers. These infections were predominantly attributed to careless handling of the contact lenses or microbial contamination of contact lens storage cases and solutions. ${ }^{1-7}$

The introduction of extended wear disposable contact lenses was meant to minimise these complication promoting factors. ${ }^{89}$ Despite the fact that contact lens handling was reduced to a minimum and contact lens storage cases and solutions were no longer a source of contamination bacterial keratitis and corneal ulcers still occurred, with a higher risk for extended wear of disposable contact lenses when compared with daily wear of soft contact lenses. ${ }^{410-18}$ The overnight wear of contact lenses was found to be the overwhelming risk factor for ulcerative keratitis. ${ }^{4} 1618$

The permeability of the corneal epithelium, the most important barrier against microorganisms and water from outside the eye, ${ }^{19}$ has been determined previously. ${ }^{20} 21$ The daily wear of soft contact lenses was found to decrease the permeability value which was attributed to the protection against the exfoliative effect of blinking. ${ }^{21}$ Accordingly the wearing of these contact lenses should result in a decrease in the risk of bacterial infection rather than an increase. On the other hand, the contact lens is applied directly on the cornea and can itself be a source of bacterial contamination. These bacteria may originally be present in the contact lens, contact lens care solution, or elsewhere and can only penetrate the cornea through a defect in its epithelial layer. ${ }^{22} 23$

Despite these findings in the daily wear of soft contact lenses it is probable that an increase in corneal epithelial permeability indicates damage to the corneal epithelium which might increase its susceptibility to bacterial invasion. Since extended wear of contact lenses induces a higher risk for bacterial infection than daily wear we hypothesise that the permeability of the corneal epithelium might be increased as a result of extended wear in comparison with daily wear, indicating the potential for bacterial invasion.

To check this hypothesis the value of the corneal epithelial permeability was measured by fluorophotometry in volunteers during daily wear of soft contact lenses and compared with the value during extended wear.

\section{Materials and methods}

VOLUNTEERS

Volunteers were recruited from an optometric practice in Leiden, the Netherlands. After explanation of the study and informed consent, selection was performed according to the following criteria: (1) intention to start wearing extended wear disposable contact lenses; (2) age between 18 and 50 years; (3) normal aspect of all corneal layers on slit-lamp biomicroscopy; (4) daily wear of hydrogel contact 
lenses (poly 2-hydroxyethylmethacrylate (HEMA) $38 \%$ water) for at least 6 months on a frequent replacement basis (every 6 months). Exclusion criteria were: (1) use of medication, with the exception of oral contraceptives; (2) diabetes mellitus or Graves' ophthalmopathy; (3) long standing wear (>10 years) of polymethylmethacrylate contact lenses in order to exclude morphological changes which could result in physiological alterations; (4) inability to cooperate.

Non-contact lens wearing volunteers were also included for comparison of the method with previous studies.

\section{MATERIALS}

The Acuvue disposable contact lens (Vistakon, Johnson \& Johnson Vision Products, Inc, Jacksonville, FL, USA), a 58\% water content hydrogel lens (Etafilcon A), was used. The fluorophotometric measurements were performed with a scanning fluorophotometer (Fluorotron Master, Coherent Radiation Inc, Palo Alto, CA, USA) fitted with a special lens, 'anterior segment adaptor', for detailed scanning of the cornea. ${ }^{2021}$ Pachymetry was performed with an ultrasound pachymeter (DHG Technology Inc, Frazer, PA, USA).

\section{METHODS}

At the end of the last 6 month period of daily contact lens wear the first determinations of corneal epithelial permeability and corneal thickness were performed as follows. A $1 \%$ fluorescein solution was applied to the eyes for 3 minutes using eyebaths, after removal of the contact lenses and biomicroscopic slit-lamp examination of all corneal layers. Then the eyes were rinsed with saline and the concentrations of fluorescein in the corneas were determined with the fluorophotometer. The permeability value was calculated using the formula $^{20}$ :

$$
P=\frac{C_{\mathrm{c}}\left(t_{\mathrm{b}}\right) \times d}{C_{\mathrm{b}} \times t_{\mathrm{b}}} \times \frac{10^{6}}{60}
$$

Where $\mathrm{P}=$ corneal epithelial permeability $(\mathrm{nm} / \mathrm{s}) ; \quad \mathrm{C}_{\mathrm{c}}\left(\mathrm{t}_{\mathrm{b}}\right)=$ corneal fluorescein concentration directly after the eyebath $(\mathrm{ng} / \mathrm{ml})$; $\mathrm{C}_{\mathrm{b}}=$ fluorescein concentration of the eyebath ( $\mathrm{ng} / \mathrm{ml}) ; \mathrm{t}_{\mathrm{b}}=$ bathing time (minutes); $\mathrm{d}=$ mean corneal thickness $(=1.25 \times$ the measured thickness in the centre of the cornea $\left.(\mathrm{mm})^{22}\right)$; $10^{6} / 60=$ factor for converting $\mathrm{mm} / \mathrm{min}$ to $\mathrm{nm} / \mathrm{s}$.

If necessary a correction for fluorescein still present in tear film was performed. ${ }^{20}$ The corneal thickness was measured by pachymetry.

Thereafter fitting of the disposable extended wear contact lenses and follow up examinations were performed by an optometrist. Replacement of the lenses took place after 7 days and 6 nights of wearing on extended wear basis. The permeability and the corneal thickness were measured again after 4 weeks of wearing these contact lenses. Since the corneal epithelium has a turnover time of about 7 days any effect of extended wear on the corneal epithelium can be expected to have occurred within this time. ${ }^{24}$

The results were statistically evaluated using the Wilcoxon paired rank test for nonparametric paired measurements since the permeability values of the contact lens wearing participants were found not to be distributed normally. The Mann-Whitney test was used for comparison between the contact lens wearers and the controls in this study. Student's $t$ test was used for comparison between the healthy controls of the study and previous studies since these groups were distributed normally. ${ }^{20} 21$

\section{Results}

Thirty three volunteers (nine men and 24 women) aged from 18 to 46 (mean $26 \cdot 8$ ) years participated in the study. Six people were excluded from the study: three wore the contact lenses for 5 weeks instead of 4 weeks, one person was non-cooperative, and two prematurely stopped wearing disposable contact lenses because of irritated eyes; no residual signs or symptoms were seen at the time of reporting (less than 1 week after removal of the contact lenses).

The corneal epithelial permeability values of the left and right eye were found to be correlated in both sessions (linear correlation coefficients $0.6, \mathrm{p}<0.005$ and $0.9, \mathrm{p}<0.0001$, respectively); consequently the mean values of both eyes were used in the study. The permeability values after extended wear of disposable contact lenses were not significantly different from those after daily, soft contact lens wear (mean values $0.032 \mathrm{~nm} / \mathrm{s}$ and $0.031 \mathrm{~nm} / \mathrm{s}$ respectively; Wilcoxon paired rank test $p>0 \cdot 5$ ) (Fig 1). No significant difference was found between the mean value of the controls in this study $(0.042(\mathrm{SD} 0.017) \mathrm{nm} / \mathrm{s})$ and that in two previous studies $(0.038(0.017)$ $\mathrm{nm} / \mathrm{s}$ and $0.040(0.017) \mathrm{nm} / \mathrm{s}$, Student's $t$ test $\mathrm{p}=0.30$ and $\mathrm{p}=0.59$, respectively)..$^{20} 21$ The permeability values of the controls in this study

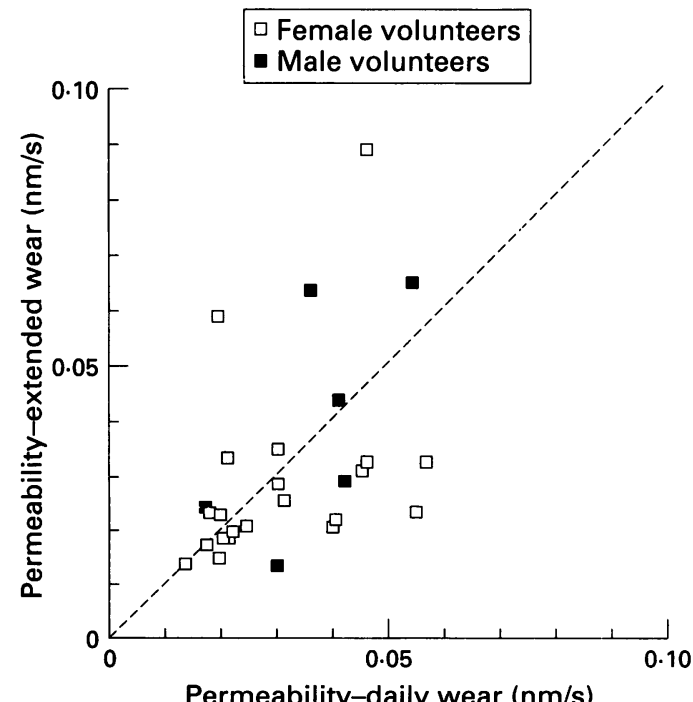

Figure 1 Corneal epithelial permeability during extended wear of disposable contact lenses versus that during daily soft contact lens wear. The broken line indicates equal permeability values. 


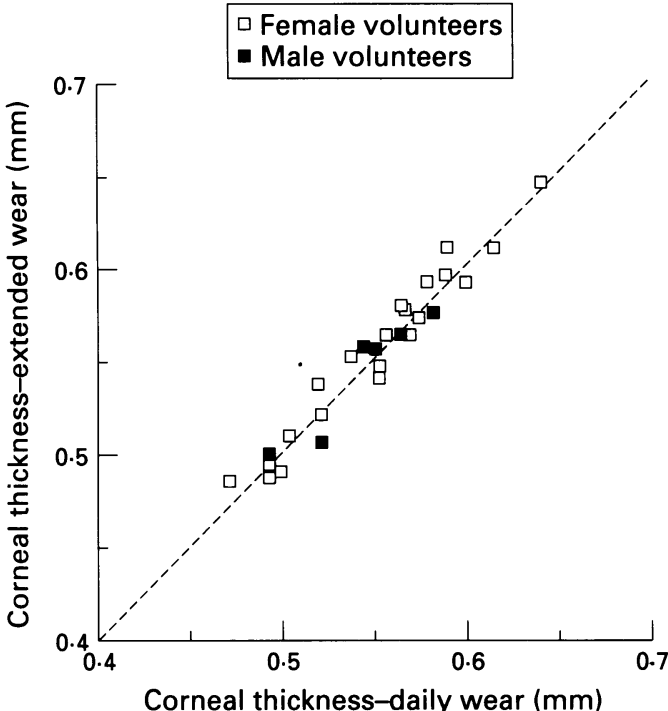

Figure 2 Corneal thickness during extended wear of disposable contact lenses versus that during daily soft contact lens wear. Broken line indicates equal thickness.

were significantly different from those after daily wear and disposable extended wear (MannWhitney test $p=0.02$ and $p=0.006$, respectively).

The values of the corneal thickness of both eyes were also correlated in both sessions (correlation coefficient $0.96, \mathrm{p}<0.0001,0.97$ and $\mathrm{p}<0.0001$, respectively). The corneal thickness values after wearing extended wear contact lenses were significantly increased in comparison with the values after daily soft contact lens wear (average increase $0.8 \%$; Wilcoxon paired rank test $\mathrm{p}=0.04$ ) (Fig 2).

\section{Discussion}

The extended wear of disposable contact lenses and the daily wear of soft contact lenses resulted in similar values of corneal epithelial permeability ( $p>0 \cdot 5)$. Twelve participants had higher permeability values during extended wear (mean increase 46\%, range 0.6-199\%) and 15 participants during daily wear (mean increase $29 \%$, range $5-57 \%$ ). If the incidence of keratitis depended on the permeability value, it would be expected to occur as frequently during daily wear as during disposable extended wear.

Unfortunately we were not able to measure the permeability immediately after lens removal of the two participants who reported irritated eyes since they reported this days after lens removal. It is possible that if the permeability was largely increased in those participants - for example, as the result of an overwear syndrome (corneal epithelial swelling and pain), this could make the cornea more prone to infection.

The significantly higher mean permeability value found in the non-contact lens wearing controls in comparison with the soft contact lens wearing participants (both daily wear and disposable extended wear) is in accordance with the results of an earlier study. ${ }^{21}$ Apparently the use of soft contact lenses protects the corneal epithelium against the exfoliative effect of blinking. ${ }^{21}$
It can be concluded that the main cause of the increased incidence of keratitis and corneal ulcers during extended wear of disposable contact lenses compared with daily wear of soft contact lenses is not a difference in corneal epithelial permeability.

Other possible causes for the increased incidence of keratitis found in wearers of extended wear contact lenses are: (1) a change of the ocular flora due to extended wear of contact lenses. Until now, no significant difference of the ocular flora between extended and daily wear had been found ${ }^{25}$; (2) an enhanced adherence of microorganisms to the corneal epithelium during extended contact lens wear. This was found for Pseudomonas aeruginosa, ${ }^{26} 2728$ which is the most common pathogen isolated from ulcers and in contact lens related keratitis ${ }^{172729}$; (3) changes in the composition of tear film such as an increased level of $\operatorname{IgA}$ in rigid gas permeable contact lens wearers, which could protect the cornea against microorganisms attached to the contact lens. Note that no increase in IgA level was found in soft contact lens wearers, resulting in an increased susceptibility to bacterial keratitis. ${ }^{30}$

The statistically significant increase in corneal thickness found in our study after the extended wear of disposable contact lenses is probably caused by the overnight wear of the contact lenses. The increase was small $(0 \cdot 8 \%)$, however, possibly is a result of a corneal adaptation process. ${ }^{31}$

Further investigations to elucidate the cause of the increased incidence of bacterial keratitis and corneal ulcers remain necessary to provide secure extended wear of soft contact lenses.

The authors thank Gerard Bijleveld and André Verhoeven, optometrists, for fitting of contact lenses and examinations.

This work was supported in part by Vistakon, a Johnson \& Johnson company, Jacksonville, FL, USA.

1 Weissman BA, Mondino BJ, Pettit TH, Hofbauer JD. Corneal ulcers associated with extended-wear soft contact lenses. Am f Ophthalmol 1984; 97: 476-81.

2 Donzis PB, Mondino BJ, Weissman BA, Bruckner DA Microbial contamination of contact lens care systems. Am f Ophthalmol 1987; 104: 325-33.

3 Tse LSY, Callender AM. Antimicrobial effectiveness of some soft contact lens care systems. Am $\mathcal{F}$ Optom Physio Opt 1987; 64: 824-8.

4 Schein OD, Glynn RJ, Poggio EC, Seddon JM, Kenyon $\mathrm{KR}$. The relative risk of ulcerative keratitis among users of daily-wear and extended-wear soft contact lenses. $N$ Engl 7 Med 1989; 321: 773-8.

5 Larkin DFP, Kilvington S, Easty DL. Contamination of contact lens storage cases by Acanthamoeba and bacteria. Br f Ophthalmol 1990; 74: 133-5.

6 Wilson LA, Sawant AD, Simmons RB, Ahearn DG Microbial contamination of contact lens storage cases and solutions. Am 7 Ophthalmol 1990; 110:m 193-8.

7 Dart JKG. Disease and risks associated with contact lenses. Br f Ophthalmol 1993; 77: 49-53.

8 Donshik P, Weinstock FJ, Wechsler S, Asbell P, Atwood J, Davis $\mathrm{H}$, et al. Disposable hydrogel contact lenses for extended wear. $C L A O$ f 1988; 14: 191-4.

9 Gruber E. The disposable contact lens: a new concept in extended wear. $C L A O$ f 1988 ; 14: 195-8.

10 Vikoren Mertz PH, Bouchard CS, Mathers WD, Goldman J, Shields WJ, Cavanagh HD. Corneal infiltrates associated with disposable extended wear soft contact lenses: ated with disposable extended wear soft contact
report of nine cases. $C L A O F$ 1990; 16: 269-72.

11 Dunn JP, Mondino BJ, Weissman BA, Donzis PB, Kikkawa DO. Corneal ulcers associated with disposable hydrogel contact lenses. Am $f$ Ophthalmol 1989; 108: 113-7.

12 Harris JK, Shovlin JP, Pascucci SE, Depaolis MD Jordan AJ. Keratitis associated with extended wear of disposable contact lenses. Contact Lens Spectrum 1989; 4 55-8.

13 Kent HD, Sanders RJ, Arentsen JJ, Cohen EJ, Laibson PR. Pseudomonas corneal ulcer associated with disposable soft contact lenses. $C L A O \mathcal{F} 1989 ; 15: 264-5$. 
14 Killingsworth DW, Stern GA. Pseudomonas keratitis associated with the use of disposable soft contact lenses. Arch Ophthalmol 1989; 107: 795-6.

15 Cohen EJ, Gozalez C, Leavitt KG, Arentsen JJ, Laibson PR. Corneal ulcers associated with contact lenses including experience with disposable contact lenses. CLAO F 1991; 17: $173-6$.

16 Bueler PO, Schein OD, Stamler JF, Verdier DD, Katz J. The increased risk of ulcerative keratitis among disposable soft contact lens users. Arch Ophthalmol 1992; 110 1555-8.

17 Matthews TD, Frazer DG, Minassian DC, Radford CF, Dart JKG. Risks of keratitis and patterns of use with disposable contact lenses. Arch Ophthalmol 1992; 110: 1559-62.

18 Schein OD, Buehler PO, Stamler JF, Verdier DD, Katz J. The impact of overnight wear on the risk of contact lensThe impact of overnight wear on the risk of contact lensassociated

19 Friend J. Physiology of the cornea; metabolism and biochemistry. In: Smolin G, Thoft RA, eds. The cornea. scientific foundations and clinical practice. 2nd ed. Boston, Toronto: Little, Brown and Company. 1987: 3-62.

20 Kruijf de EJFM, Boot JP, Laterveer L, Best van JA, Ramselaar JAM, Oosterhuis JA. A simple method for determination of corneal epithelial permeability in humans. Curr Eye Res 1987; 6: 1327-33.

21 Boets EPM, Best van JA, Boot JP, Oosterhuis JA. Corneal epithelial permeability and daily contact lens wear as determined by fluorophotometry. Curr Eye Res 1988; 7: 511-4.

22 Stern GA. Pathogenesis of contact lens-associated Pseudomonas corneal ulceration. In: Dwight
Cavanagh $\mathrm{H}$, ed. The cornea transactions of the world congress on the cornea III. New York: Raven Press, 1988: 309-11.

23 Klink van $\mathrm{F}$, Alizadeh $\mathrm{H}, \mathrm{He} \mathrm{Y}$, Mellon JA, Silvany $\mathrm{RE}$, McCulley JP, et al. The role of contact lenses, trauma, and Langerhans cells in a Chinese hamster model of Langerhans cells in a Chinese hamster model of
Acanthamoeba keratitis. Invest Ophthalmol Vis Sci 1993; 34: 1937-44.

24 Lemp MA, Mathers WD. Renewal of the corneal epithelium. CLAO f 1991; 17: 258-66.

25 Elander TR, Goldberg MA, Salinger CL, Tan JR, Levy B, Abbott RL. Microbial changes in the ocular environment with contact lens wear. $C L A O \mathcal{F}_{1} 1992 ; 18: 53-5$.

$26 \mathrm{Klotz}$ SA, Misra RP, Butrus SI. Contact lens wear enhances adherence of Pseudomonas aeruginosa and binding of lectins to the cornea. Cornea 1990;9: 266-70.

27 Fleiszig SMJ, Efron N, Pier GB. Extended contact lens wear enhances Pseudomonas aeruginosa adherence to human enhances Pseudomonas aeruginosa adherence to human
corneal epithelium. Invest Ophthalmol Vis Sci 1992; 69: 354-7.

28 Slusher MM, Myrvik QN, Lewis JC, Gristina AG. Extended-wear lenses, biofilm, and bacterial adhesion. Arch Ophthalmol 1987; 105: 110-5.

29 Schein OD, Ormerod LD, Barraquer E, Alfonso E, Egan KM, Paton BG, et al. Microbiology of contact lens-related keratitis. Cornea 1989; 8: 281-5.

30 Temel A, Kazokoglu H, Taga Y, Orkan AL. The effect of contact lens wear on tear immunoglobulins. CLAO $\mathcal{f}$ 1991; 17: 69-71.

31 Armitage BS, Schoessler JP. Overnight corneal swelling response in adapted and unadapted extended wear patients. Am f Optom Physiol Opt 1988; 65: 155-61. 